\section{Depression and Quality of Life in Patients With Amyotrophic Lateral Sclerosis}

by Dr. rer. nat. Dorothée Lulé, Dipl. Psych. Sonja Häcker, Prof. Dr. med. Albert C. Ludolph, Prof. Dr. phil. Niels Birbaumer, PD Dr. rer. nat. Andrea Kübler in volume $23 / 2008$

\section{Special Motivation}

The published data confirm my own experiences, namely, that many people with the most severe physical impairments experience their lives as complete and often give them a satisfactory shape. During my time as a medical doctor, I have had the opportunity to learn much from my patients about what constitutes "real" life. However, there are also people with severe illness who are desperate-whom I failed often, and who taught me to be modest and live with the knowledge of my own powerlessness. Which patient belonged to which group depended less in the degree and type of their illness but on their social network, their attitudes to their own past and future, and personal values.

We know from palliative medicine and hospice work that comprehensive explanations about the disease and its progression, therapeutic options or the lack therefore, and holistic care can reduce fears and improve quality of life. The fact that lacking representativeness was mentioned and the numbers of participants were low makes me question some of the conclusions. The study subjects must have been unusually motivated (readiness to participate in the study, dependence on ALS outpatient clinics) patients, who benefited from the comprehensive care that is recommended in the conclusion. Unfortunately, no information was provided about age, social networks, or subjects' philosophy of life. I think it is not justified to conclude "a satisfactory quality of life even if they are severely physically impaired, [...]"is possible in any stage of ASL. This statement includes patients undergoing invasive ventilation. It also suggests that high quality information might increase patients' willingness to undergo therapeutic measures "including invasive ventilation". This is overstating the case, in view of the very small number of patients receiving invasive ventilation $(n=4)$. Using the study results as instruments in the controversy about the validity or scope of advance directives (as has happened in the press) seems inappropriate.

DOl: 10.3238/arztebl.2008.0825b

Dr. med. Jürgen Bickhardt

Uhlandstr. 19

85435 Erding, Germany on on the part of the patient to stop treatment should not be put into question or stigmatized as a result of overinterpreting the results of the study under discussion.

\author{
REFERENCES \\ mungstherapie bei der Amyotrophen Lateralsklerose. Nervenarzt \\ 2008; 79: 684-90. \\ Prof. Dr. med. Thomas Meyer \\ Charité - Universitätsmedizin Berlin \\ Neurologische Klinik \\ Ambulanz für ALS und andere Motoneuronenerkrankungen \\ Augustenburger Platz 1 \\ 13353 Berlin, Germany \\ thomas.meyer@charite.de
}

1. Meyer T, Dullinger JS, Münch C et al.: Elektive Beendigung der Beat-

\section{In Reply:}

We thank Bickhardt and Meyer for their correspondence. We concluded from our data that an individual perspective of patients' individual situations is important and that a simple deductive conclusion from the extent to which quality of life and affective situation are compromised is impossible. We therefore welcome information about others' experiences that were not captured in our statistically based discussion. Anyone dealing with ALS knows that such patients exist and that they deserve all the respect and care that Bickhardt and 
Meyer rightly demand. On the basis of international literature and results from our study group as well as other samples of ALS patients (1-4) we conclude, however, that patients' quality of life statistically barely deviates from that in the healthy population, even in late stages of the illness and under ventilation. The fact that contrasting examples are found in clinical practice is due to the nature of quantitative methods. Individual experience is not a scientific criterion. It is for this reason that Bickhardt and Meyer in their remarks have underlined our conclusions that individual patients have a right to depressive, autoaggressive, and euphoric phases; these should be treated according to medical and clinicalpsychological parameters and not merely accepted as fate.

Another observation made by ourselves as well as others may serve to strengthen our case: the often observed phenomenon that the outer perspective differs significantly from the inner perspective. A patient with-even severe-disabilities assesses his or her quality of life as clearly better than a healthy observer does $(4,2)$.

As we mentioned and are aware, our study has limitations (patients' dependence on highly specialized outpatient departments, patients' willingness to participate in the study), and future studies will have to fill in the gaps (we are currently conducting such studies-which also takes into account the situation in the Netherlands, by comparison). The criticism of our case numbers is understandable; but using statistical methods is an attempt to overcome the disadvantages associated with small numbers, and our conclusions are based on just such methods.
We hope that we have prompted discussions the quality of life of ALS patients, but also of that of other population groups with severe disabilities.

DOI: 10.3238/arztebl.2008.0826

\section{REFERENCES}

1. Birbaumer N, Cohen L: Brain-Computer-Interfaces (BCl): Communication and Restoration of Movement in Paralysis. The Journal of Physiology 2007; 579: 621-36.

2. Kübler A, Winter S, Kaiser J, Birbaumer N, Hautzinger M: Ein Fragebogen zur Messung von Depression bei degenerativen neurologischen Erkrankungen (amyotrophe Lateralsklerose). [An inventory to measure depression in neurodegenerative diseases (amyotrophic lateral sclerosis)]. Zeitschrift für Klinische Psychologie und Psychotherapie 2005; 34: 19-26.

3. Kubler A, Winter S, Ludolph AC, Hautzinger M, Birbaumer N: Severity of depressive symptoms and quality of life in patients with amyotrophic lateral sclerosis. Neurorehabil Neural Repair 2005; 19: 182-93.

4. Trail M, Nelson ND, Van JN, Appel SH, Lai EC: A study comparing patients with amyotrophic lateral sclerosis and their caregivers on measures of quality of life, depression, and their attitudes toward treatment options. J Neurol Sci 2003; 209: 79-85.

\section{Prof. Dr. med. Albert C. Ludolph}

Neurologische Klinik der Universität Ulm im RKU

Oberer Eselsberg 45

$89081 \mathrm{Ulm}$, German

albert.ludolph@rku.de

\section{Conflict of interest statement}

The authors of all letters and of the reply declare that no conflict of interest exists according to the Guidelines of the International Committee of Medical Journal Editors.

\section{Declaration}

The study subjects gave written consent to participate in the study. The studies were approved by the ethics committees at the universities of UIm and Tübingen. 